\title{
Modeling of Runoff in the Arid Regions Using Remote Sensing and Geographic Information System (GIS)
}

\author{
Ahmed Shahadha Muneer*, Khamis Naba Sayl, Ammar Hatem Kamel \\ Dams and Water Resource Department, College of Engineering, University of Anbar, Ramadi 31001, Iraq
}

Corresponding Author Email: ahmedshahadha_ded@uoanbar.edu.iq

https://doi.org/10.18280/ijdne.150511

Received: 18 May 2020

Accepted: 29 August 2020

\section{Keywords: \\ runoff, infiltration, Geographic Information System (GIS), Remote Sensing (RS), Artificial Neural Network (ANN), Soil Conservation Service-Curve Number (SCS-CN), water resources management}

\begin{abstract}
One of the most important challenges in the field of engineering hydrology and water resources management, especially in arid regions such as the Iraqi Western Desert, is the process of predicting and quantifying the surface runoff. The limited available data about rainfall, runoff, soil properties, evaporation, and the lack of metrological stations make the process of predicting and calculating surface runoff a very difficult task. Modern technology can help with the purpose of compensating for the shortage of data and providing the information necessary to estimate the runoff and develop the system of water resources management in the region. The present study develops a model to determine the infiltration of soil from spectral reflectance using Artificial Neural Networks (ANN) integrated with a geographic information system (GIS) and remote sensing (RS). Field infiltration measurements for 105 soil samples in the Al-Ratga catchment area in the Iraqi western desert are achieved. The performance of the developed model was assessed both qualitatively and quantitatively (effective runoff depth) by comparing the results of actual and estimated basic infiltration rate values for each sample. The results refer to a good agreement between estimated and measured infiltration $\left(\mathrm{R}^{2}=0.768\right)$. The developed model predicts the runoff depending on the water balance equation and the results refer to good agreement with the SCS-CN model that is one of the most widely used in this region.
\end{abstract}

\section{INTRODUCTION}

The poorly invested for water resources as well as poorly known of decision-makers about these resources are the main problems in arid regions like Iraqi western desert. In the Iraqi western desert, the scarcity of surface water resources, and the high cost of groundwater investment because of its depth 200 $m$ depth in some region, need special effective water resources management $[1,2]$. The random nature of the hydrologic cycle such as short-duration, high-intensity patterns of rainfall, and spatially distribution causes highly variable with more extreme for the hydrological regime [3-5]. The limited data are the most important restrictions for studies and researches that lead to little expert knowledge and raise an important scientific and technical challenge of water resources management in this region. Studies and understand the hydrological responses are essential for efficient planning of water resources to satisfy current and future needs. Unfortunately, most of these regions suffer from a lack in the number of rain gauge and meteorological stations because of a lack of human and financial resources as shown in Figure 1. Table 1 shows the location of meteorological stations in and around Iraqi western desert with average annual rainfall in $\mathrm{mm}$. In these stations, the data available for rainfall, evaporation, and runoff flow rate that are necessary for reliable hydrological analysis are incomplete, discontinuous, and short-lived.

The most of watersheds in these regions are so large and remote with poorly of infrastructures like roadway that makes it is so difficult to monitoring and set the metrological stations in the region. The highlighted problem in the arid zones is also a rarity of hydrological models because the rainfall series are available but with gaps [6]. Technology can help to provide solutions for the lack of data by using rainfall-runoff modeling as one of these solutions to overcome these problems. Therefore; there is interesting necessity to develop and use the rainfall-runoff models that help of predicting the water harvesting in any catchment area from the available rainfall data. Surface runoff prediction in the arid region considered an important challenge in hydrology, especially for the ungagged area when further studies to develop and improve the runoff prediction models are necessary $[7,8]$. Because of the data is so limited and, in many times, not available, it is necessary to use other approaches for resorting representative runoff in catchment area.

Table 1. Metrological station in and around studied area

\begin{tabular}{|c|c|c|c|c|c|}
\hline \multirow[b]{2}{*}{ Station } & \multicolumn{2}{|c|}{ Location } & \multicolumn{2}{|c|}{ Observations } & \multirow{2}{*}{$\begin{array}{l}\text { Rainfall } \\
\mathrm{mm} / \text { year }\end{array}$} \\
\hline & Longitude & Latitude & $\begin{array}{c}\text { Begin } \\
\text { Data }\end{array}$ & $\begin{array}{l}\text { End } \\
\text { Data }\end{array}$ & \\
\hline Rutba & 40.17 & 33.02 & 1928 & 2016 & 113.22 \\
\hline Nukhaib & 42.27 & 32.03 & 1939 & 2016 & 70.36 \\
\hline Haditha & 42.22 & 34.04 & 1937 & 2014 & 128.10 \\
\hline Ana & 41.97 & 34.36 & 1951 & 2016 & 130.00 \\
\hline
\end{tabular}




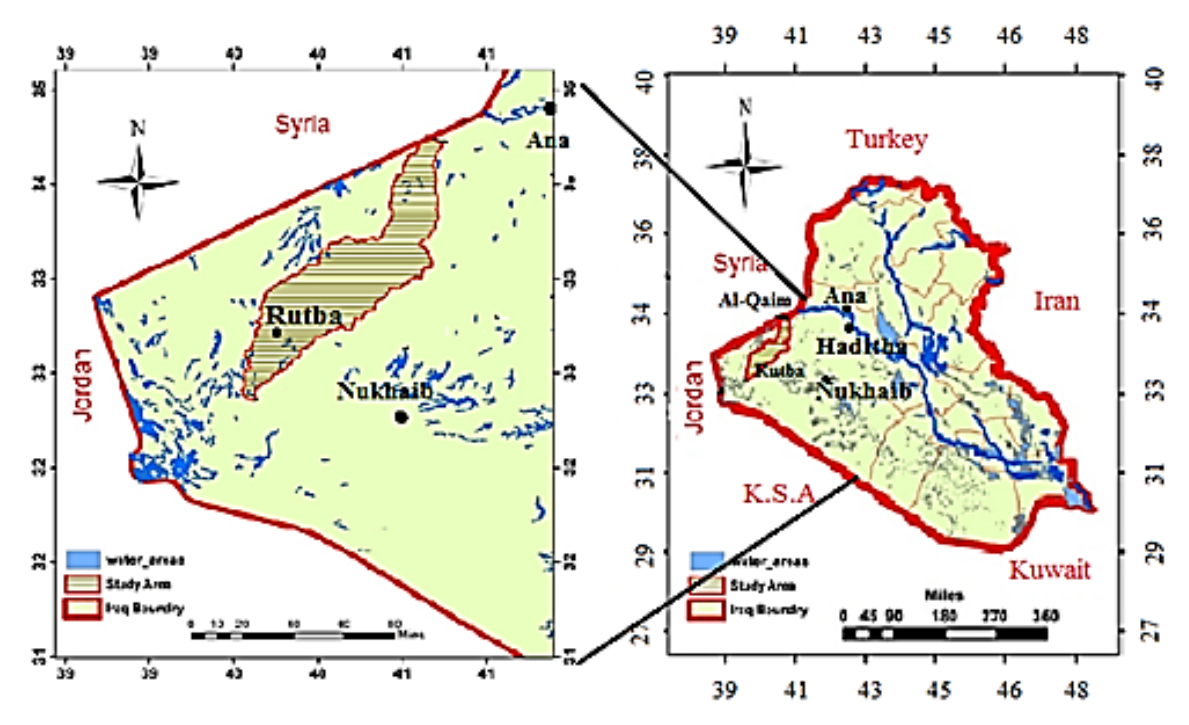

Figure 1. Metrological stations in Iraqi western desert

The rainfall-runoff models have been applied in the ungagged arid regions to predict runoff in many studies over the world. In 1932, Sherman presented the concept of the unit hydrograph that now define as a discharge hydrograph representing $1 \mathrm{~mm}$ or $1 \mathrm{~cm}$ of effective rainfall or direct runoff [9]. It is assumed the rainfall is distributed regularly over catchment area at a uniform rate during a certain time. The Sherman model considers the integrated effects of constant physical characteristics of the catchment area such as area, length of stream channel and slopes on the runoff. The relevant features of the unit hydrograph would be assumed to be identified with the physical qualities of the catchment area. In 1938, Snyder studied many catchments areas with varying sizes from 30 to $30000 \mathrm{~km}^{2}$ in the united states and concluded synthetic relations to describe characteristics of a standard unit hydrograph (peak flow rate, base time, effective rainfall duration ...etc.) [10]. This method or model is known as a synthetic unit hydrograph and from these relationships, a required unit hydrograph for a given effective rainfall duration can be evaluated. A synthetic unit hydrograph is used to develop unit hydrograph for the ungagged area has a similar character or nearby the catchments where the synthetic unit hydrograph was developed and consider the first model for predicting the runoff from rainfall for ungagged area. Kamel applied the unit hydrograph theory to evaluate the runoff volume for many large catchments areas in Iraqi western desert based on historical measured data in the region [11]. Unit hydrograph theory need details data for rainfall and runoff flow rate in the catchment area has a similar character or nearby ungagged catchment for derivation and application that are so limited in the arid region. Also, it is so difficult to satisfy its assumption of uniform rainfall intensity overall catchment because of the wide extent of catchments area in the western desert of Iraq. In these catchments, the conceptual models are widely used for runoff predictions and depend on the rainfall-runoff relations [12]. These models require flow rate data (storm rainfall hydrograph) for calibration and verification. Abdulla et al. [13] applied the single event watershed model with (Resonbrock optimization technique) for two catchments in Iraqi western desert. The water balance equation is used to simulate and predict the surface runoff depends on rainfall, evaporation, and soil properties as input data. Because limited data the sensitivity analysis had been used to estimate the most sensitive parameters. The reservoir water balance was applied to calibrate a rainfall-runoff model for the ungagged catchments area in Zimbabwe [14]. The increase in water level resulted from a rainstorm event is related to the dimensions of the reservoirs for runoff prediction. Liebe et al. [15] used a remote sensing technique to relate the time series surface areas of a reservoir to estimate the volume of the reservoir that is calculated from the changes in the storage reservoir. This volume was used for calibration and verification runoff in the water balance model in Ghana. The expensive or high cost of satellite images were the major challenges and limitations of the study. Aljawad and Alansari [16] applied the Soil Conservation Service-Curve Number (SCS-CN) method using single rainfall storm events to evaluate the annual runoff volume in the Horan catchment area that considers a major valley in the Iraqi western desert. The method is validated depends on actual past runoff observations which have concluded that runoff may exceed $69 \mathrm{~mm}$ depth in a single water year. The average depth of runoff is about 11.1 $\mathrm{mm}$ with $64 \mathrm{Mm}^{3}$ as potential water harvesting. Sulaiman et al. [2] used the remote sensing and numerical analytical tools for predicting the runoff to assess water resources in the Iraqi western desert depending on field measurements of hydrogeological parameters applying SCS method.

Rainfall in the Iraqi western desert is typically low average (Table 1), irregular and highly variable and rainfall-runoff relation is affected widely by infiltration excess. The initial infiltration reaches final infiltration rates after a short time because of a fast response due to shallow soils, steep hillslopes, exposed rocks and lack of vegetarian cover. The catchment includes stream channels that have alluvial beds that causes reduce the flood volume due to infiltration of floodwater during surface flow. There is another part of the catchment area with rocky channel beds that make this process is not significant [17]. Therefore; the infiltration rate is different from location to other depends on soil properties in the catchment. The development of the rainfall-runoff model to simulate and estimate the amounts of runoff in the Iraqi western desert is a challenging task for several reasons. The model requires detailed important data for example stream flow data for calibration and verification that is not available in this region [18]. Also, to estimate the infiltration rate and runoff or excess rainfall, the intensity of storm rainfall data and 
its durations are so important. Since 1954, the Soil Conservation Service curve number (SCS-CN) method is the most widely used in hydrology to predict runoff from rainfall based on an expression for a rainfall-runoff curve. This curve varies depending on a single dimensionless parameter that is known the curve number $(\mathrm{CN})$. It describes the preceding possible water retention of a catchment. The $\mathrm{CN}$ is tabulated for different hydrologic conditions, land use, and soil types that make it easy to devolve GIS data into rainfall-runoff models based on the SCS-CN method [19]. This method is developed based on local farming sites data in Midwest district of the United States and constrained by its empirical origins. Although many studies continue to use the SCS-CN method over the world, it cannot be readily or simply transferred to catchment areas outside the regions where it is developed. The SCS-CN method applies well in humid regions but it applies fairly for rangeland and it reflects runoff mechanisms in these regions which may be dominated by the subsurface flow and attuned to saturation excess mechanism. The infiltration excess mechanism dominates in the Iraqi western desert that is so different from the saturation excess mechanism. The SCS$\mathrm{CN}$ method has lacked a description of the runoff spatial variability therefore this method has assumed a homogeneous catchment area with runoff spatially uniform. The large area of the catchment, as well as the little number of metrological stations or rain-gauge, make spatial distribution of rainfall is not efficiently represented over all the catchment area and leads to significant errors in the prediction of the source area of runoff.

To move beyond the limitations and problems of above methods and models, the present study develops a new practical and theoretical approach for spatially rainfall-runoff modeling based on GIS and remote sensing data. The spatial inflation model is developed as a basis of runoff prediction modeling depending on field observations and measurements. The infiltration rate is measured overall catchment area using the double-ring method to provide data for the modeling process. The remote sensing technique determines a spectral reflectivity of soil in the region that is related to measured data for developing a relationship for predicting the infiltration rate in ungagged location. Then water balance equation is applied to evaluate the spatial runoff depth map for the studied area.

\section{STUDY AREA}

Wadi AL-Ratga is one of the main valleys in Anbar province located at the western plateau of Iraq, with longitude of $39^{\circ} 38^{\prime} 11^{\prime \prime}$ to $40^{\circ} 46^{\prime} 46^{\prime \prime} \mathrm{E}$ and Latitude $32^{\circ} 47^{\prime} 7^{\prime \prime}$ to $34^{\circ} 17^{\prime}$ $41^{\prime \prime} \mathrm{N}$ as shown in Figure 1. The total watershed area inside Iraq border is about $5579 \mathrm{~km}^{2}$ and $524 \mathrm{~km}$ perimeter. Wadi AlRatga basin flows into the Euphrates River inside Syria border. This area was selected because the current orientation for rainwater harvesting and the possibility of investment in the future.

Principally, the climate of the western plateau of Iraq is semi-continental and is located within arid zones, where its hot dry in summer and cold rainy in winter, with rainfall amounts vary from year to year. There is also a variation in temperatures during the day and night. The climate of the study area is characterized by an arid climate via analyzing the climate data including temperature and average rainfall of the Rutba and Al-Qaim stations. The average annual perception is very low $143 \mathrm{~mm}, 146.7 \mathrm{~mm}$ respectively for both Rutba and
Al-Qaim stations [20]. The maximum average annual temperature is $31.6^{\circ} \mathrm{C}, 33.8^{\circ} \mathrm{C}$ respectively for both Rutba and Al-Qaim stations recorded in July, where the minimum average annual temperature, typically recorded in January, is $7.5^{\circ} \mathrm{C}, 7.8^{\circ} \mathrm{C}$ respectively for both Rutba and Al-Qaim stations. The average annual evaporation is $3300 \mathrm{~mm}$. the study area elevations of the lowest and highest are 268 and $836 \mathrm{~m}$ above sea level, where this elevation decreases moving northward. The average basin slope is 0.0095 ; maximum stream length is $220 \mathrm{~km}$; the shape factor is 3.73 .

\section{METHODOLOGY}

The percent study describes the process of spatially rainfallrunoff molding and developing an integrated approach that includes Remote Sensing (RS), Geographic Information System (GIS), field measurements, and Artificial Neural Network system (ANNs) to achieve these objectives. The first step is using satellite images of the study area from Landsat 8 in 20/6/2019 and Digital Elevation Model (DEM) generated from Shuttle Radar Topographic Mission (SRTM) data, which is used as input to extract the watershed basin. For geometric corrections these images were imported into ArcGIS 10.7 package using WGS 84, UTM zone 37. Unsupervised classification is carried out to sort pixels into a limited number of categories based on their data values [21]. Based on the values of reflective intensity of the entire study area, the soils of this area were classified into ten classes (Figure 2).

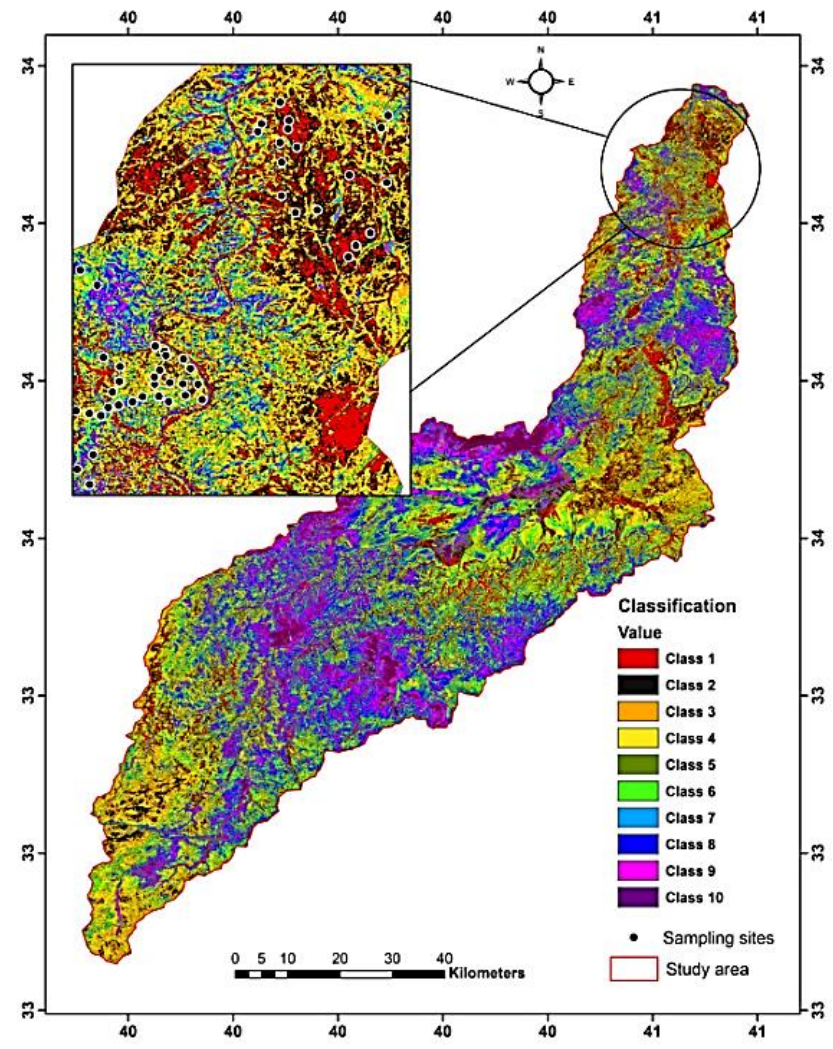

Figure 2. Soil classes unsupervised classification with samples location

Each class shows a specific distribution based on the Gaussian function of normal distribution [22]. Unsupervised classification can be utilized as pre-processing prior to acquire a knowledge of main classes and can be preferred if the area is 
too large [23]. It is a helpful task and involving making primitive map for preliminary survey for of the soil and to identify soil sampling locations to diminish the cost and time effort. This primitive map is produced by color-coding each pixel to represent the category in which it is assigned by the classification algorithm.

Subsequently, based on thematic maps from unsupervised classification, the locations of infiltrations test have been selected. By using a GPS device, a hundred-five (105) test locations were selected throughout the study area based on specific criteria, i.e. slope, soil roughness, topography, water, roads, and urban areas to diminish as much as possible the error in pixel. After site investigation for water infiltration test were carried out, Landsat 8 satellite imagery is used to locate the spectral reflectance at each selected location using Arc GIS based on the actual locations identify by the GPS instrument. Spectral reflectance of nine bands, represented by visible wavelength (B1 $(0.43-0.45 \mu \mathrm{m}), \mathrm{B} 2 \quad((0.45-0.51) \mu \mathrm{m})$, B3(0.53-0.59) $\mu \mathrm{m}, \mathrm{B} 8(0.50-0.68) \mu \mathrm{m}$ and B4 (0.64- 0.67) $\mu \mathrm{m})$, near-infrared (B5 (0.85-.088) $\mu \mathrm{m})$, and short-wavelength ( B6 (1.57 - 1.65) $\mu \mathrm{m}, \mathrm{B} 7$ (2.11-2.29) $\mu \mathrm{m}$, and B9 (1.36-1.38) $\mu \mathrm{m})$ is recorded at each selected point while two thermal infrared bands are reduced. The double ring test is carried out in the situ to measure the infiltration rate of soil according to the double ring infiltrometer [24, 25].

Currently, Radial Basis Function-based Neural Networks (RBF-NNs) is used in most applications such as hydrological modeling which require modeling of non-linear connections of input and output. RBF-NNs are simpler processor networks composed of receptive units (neurons) that run in parallel. They are made up from three layers: a layer of inserted (input) neurons that feed the feature vectors into the network; a hidden layer of RBF neurons that computes the results (outcome) of the basic functions; and the output neurons layer which calculates linear combinations of the basic functions (Figure 3).
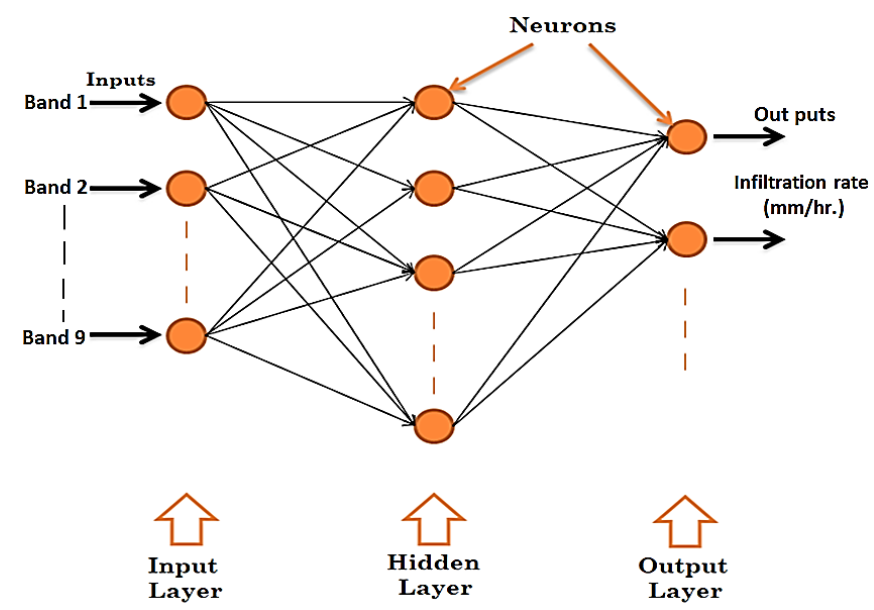

Figure 3. RBF-ANN layer structure

Each layer has a different number of neurons [26]. RBFNNs give almost of any relationship of input/output as a linear set of the radial basis functions (RBF). Neurons receive their input through bonds that multiply the strength of each bond by its scalar weight and increase a bias. All inputs are weighted and its weights become input transfer function that produces neuron output. By modification the connection weights and biases, the network can display almost all of the desired outputs. This process is called the training process. ANN also shows some ability to generalize beyond training data. In present study, various numbers of hidden layer neurons and spread constants are examined. The spread is a constant is 0.01 which was chosen before RBF simulation. RBF-NNs trained with descent methods can do the equivalent or better than other methods. The decent gradient method is slow in convergence because it cannot effectively use locally matching representations of hidden layer elements. During gradient descent training, weights are adjusted at each step and move in the opposite direction to the slope of the objective function (where a minimum of objective functions can be found) [26].

After the infiltration rate measurements and the spectral reflectance for nine bands recorded, the infiltration rate measurement data by double ring method of the selected point and the spectral reflectance values for nine bands correspond to the actual locations samples have been utilized for training, validation and testing of RBF-NNs models. In the experimental fields, several approaches have been applied by different researchers for identify of suitability models. Minimize difference between the measured and predicted values is one of the simplest methods to find the suitable model prediction. To evaluate the performance of this model, the commonly statistical performance indices such as root mean square error (RMSE), mean absolute error (MAE), relative error (RE) and mean absolute percentage error (MAPE) have been used to checking the accuracy of the prediction model during testing period [27]. Also, the Nash-Sutcliffe efficiency (also called model efficiency) (ME) have been used to checking the goodness of the ANN model performance. This index commonly used in hydrological models assessment, it can be effectively used to compare the relative performance of two approaches [28]. Similarly, the coefficient of determination $\left(\mathrm{R}^{2}\right)$ was used as an indicator of closeness degree between measured and simulated values.

Based on the ANNs model and the spectral reflectance values for 1105 locations distributed to all study area, the results of RBF-NNs model were manipulated within ArcGIS using spatial analyst model to generate a digital map of infiltration rate. This map was used as the base to generate the runoff digital map for entire area. Finally, the water balance equation is applied to evaluate the spatial runoff depth map for the studied area. Figure 4 shows the developing model used in present study.

\section{RESULTS AND DISCUSSION}

The unsupervised classification gave a distinct thematic map for the land cover, which enabled to select the suitable sample locations carefully, so cost and time reduced. As shown in Figure 2, the land cover of the catchment area was sorted into ten classes, which represented by distinct colures. Each class gives a certain range of the values of spectral reflectivity, which is expressed in digital number. The spectral reflectance of nine bands for each infiltration test location was recorded using ArcGIS. The infiltration measurement with a double ring method is achieved at these suitable sample locations. The results of the infiltration measurements, of 105 samples, show that the values of the basic infiltration rate are varying from 12 to $27.8 \mathrm{~mm} /$ hour. 


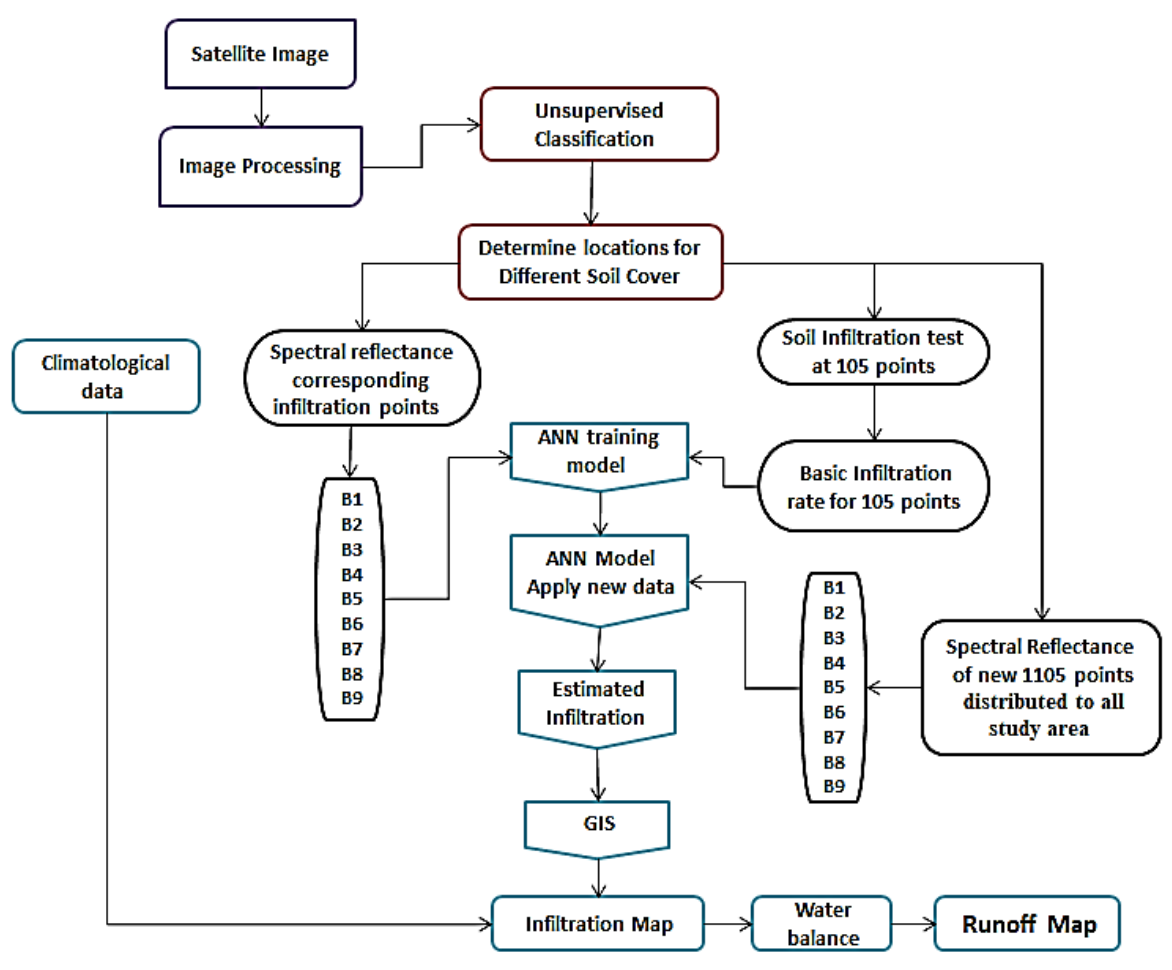

Figure 4. Flowchart of developing model

There is no commonly acceptable criterion by which a model can be viewed as plausible or not plausible. This consideration mainly depends on the model application. Therefore, the hysteresis argument of model assessment is comparatively general. After estimating the infiltration based on the proposed model in the present study, the issues need to be evaluated so as to affirm the model validity. The virtual test of the model is its capability to predict system response (infiltration) for the region in the same location for the measured samples. This test was made by using the remote sensing data (spectral reflectance) of the selected locations to evaluate the infiltration for the studied area. The agreement between evaluated and measured (actual) infiltration was explained in Figure 5 for 22 samples. The qualitative performance of the developed model was assessed by comparing results of actual and estimated basic infiltration rate values for each sample for testing period (Figure 5). It can be noted that the sequences of estimated basic infiltration rate are approximately matching the actual basic infiltration rate sequences for testing RBF, as observed results from the model testing period obviously indicate that the model can get a good accuracy for estimating infiltration rate.

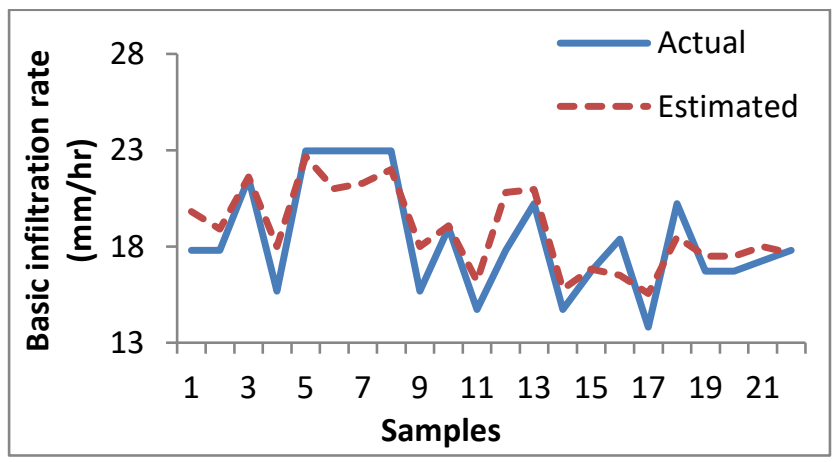

Figure 5. Comparison of actual and estimated basic infiltration rate during testing for RBF-NNs
The performance evaluation results indices values from the RBF based ANN models have been calculated. During testing period, the values of RMSE, MAE and MAPE were found 1.41, 1.15 and $0.652 \mathrm{~mm} /$ hour respectively. Also, the Nash-Sutcliffe efficiency (ME) give meaningful values were found $74 \%$, this value was found to be in the acceptable range [29].

The R-square were found 0.768 for testing period based on RBF model. This value gives an acceptable value. Furthermore, the results were supported by the relative error (RE \%), as shown in Figure 6. The (RE \%) distribution for 22 samples was less than $17 \%$. In general, the relative error between estimated and actual value shows a remarkable agreement.

The predicted digital infiltration map for entire study area was produced based on spectral reflectance of 1105 locations in study area using ArcGIS with spatial analyst model. Figure 7 shows that the distribution of the basic infiltration rate is varying from 12 to $29.5 \mathrm{~mm} /$ hour.

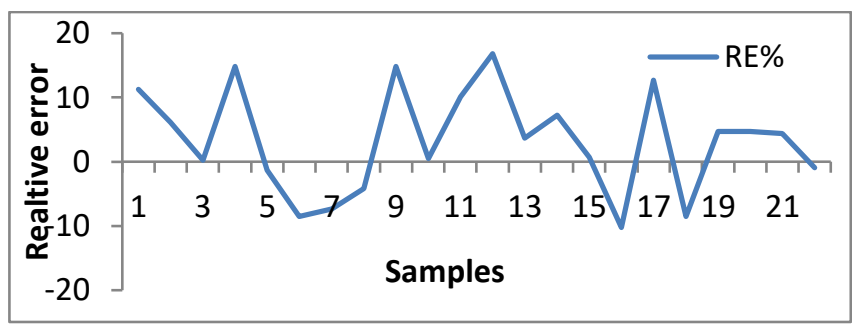

Figure 6. The (RE \%) distribution for testing period

The evaluated values can be considered as actual measured values or observation values because of resulted from field measurement. The digital infiltration map has been corrected by removing distortions. This distortion resulting from features that represented roads, rural lands, rocks, etc. The water balance equation is applied to predict the runoff volume in the studied area based on rainfall and evaporation recorded 
data from the metrological station in the region. Based on the infiltration map and the available data of rainfall and evaporation for seasons 2018/2019 and 2019/2020, the runoff depth map was prepared depended on following equation:

$$
Q=P-F-E
$$

$Q:$ Runoff Depth(mm);

$P$ : Rainfall (mm);

$F$ : Infiltration (mm);

$E$ : Evaporation(mm).

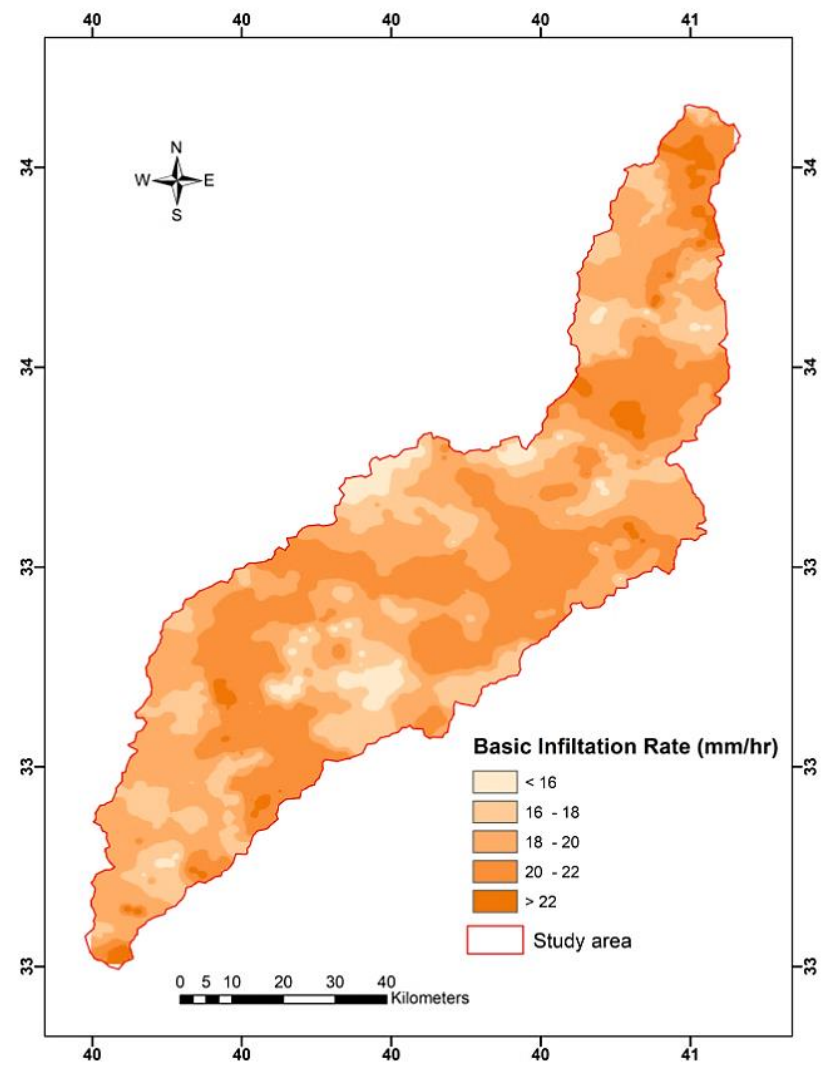

Figure 7. Infiltration map of the Study area

Presently, in addition to substantial criteria in the development of hydrologic modeling will be compared with the performance worth of different models. Two indicators have rendered comparisons sometimes Knotty. The first one is that several modelers display their results in various styles because they have the differing conceit of performance of their objectives and criteria. However, at least one direct comparison should be tolerable between emanations of various models. The second indicator of the simulation process is seldom applied to the same catchment area by different modelers. To satisfy any faithfully pointed comparisons, models should be confronted on coincident data representing a feasible extent at hydrological investigations. Therefore; to estimate the accuracy of the model developed in this study, the results are compared with the SCS method using observation data for seasons 2018/2019 and 2019/2020 (Table 2) as shown in Figures 8-13.

In the 2018-2019 and 2019-2020 seasons, the researchers were unable to install rain gauges and calculating the flow of surface surfaces. Most of the region is still restricted in movement and difficult to move and measure in it due to the events that occurred in ISIS's control of most of these areas and then liberated by government forces. So, the analysis of data for measurement stations near the study area in addition to field observations of the population in the region is adopted. Based on the observations and data recorded in these stations from the Iraqi meteorological department and seismic monitoring, it is very difficult to assume that the surface runoff is regular even for the catchment that has the same curved number. There is a clear variation in the amounts of rainfall on the area as well as the effect of the absence of Metrologicstations distributed over all the catchment areas that make the estimation of average rainfall for the catchment areas is so difficult. The present model was compared with the SCS model. Inspection of the presented runoff depth in this figure interprets that the present model has a good agreement with the SCS model for the predicted data of the runoff depth. The SCS-CN method has lacked a description of the runoff spatial variability therefore this method has assumed a homogeneous catchment area with runoff spatially uniform. The large area of the catchment, as well as the little number of metrological stations or rain-gauge, make spatial distribution of rainfall is not efficiently represented over all the catchment areas and leads to significant errors in the prediction of the source area of runoff.

The present model gave agreements with the observation of the locals more than the SCS-CN method. This method required detailed data that make the present model more efficient, simpler, and more economical in comparison with it.

Table 2. Average rainfall in the area under study

\begin{tabular}{cc}
\hline Date & Rainfall $(\mathbf{m m})$ \\
\hline $6-11-2018$ & 29.6 \\
$28-1-2019$ & 24.4 \\
$25-3-2019$ & 30.3 \\
$20-4-2019$ & 17 \\
$22-1-2020$ & 17.5 \\
$25-1-2020$ & 18.2 \\
\hline
\end{tabular}

\section{CONCLUSIONS}

The main conclusions from present study:

(1) The infiltration of soil is estimated based on spectral reflectivity with an acceptable range of performance compatibility between the results of the developed model and the field-measurement data of infiltration can be used with confidence to estimate infiltration in remote desert areas.

(2) The model can be effectively used to predict the infiltration rates without field tests which mean it saves cost and time with good accuracy. The accurate estimation of infiltration that considers the most important parameter in the arid region is achieved; the accurate estimation of runoff depth is predicted depend on the water balance equation.

(3) Artificial neural networks with remote sensing can develop a numerical model to provide engineers with tools that have acceptable accuracy for runoff estimation in an arid region like the Iraqi western desert. 

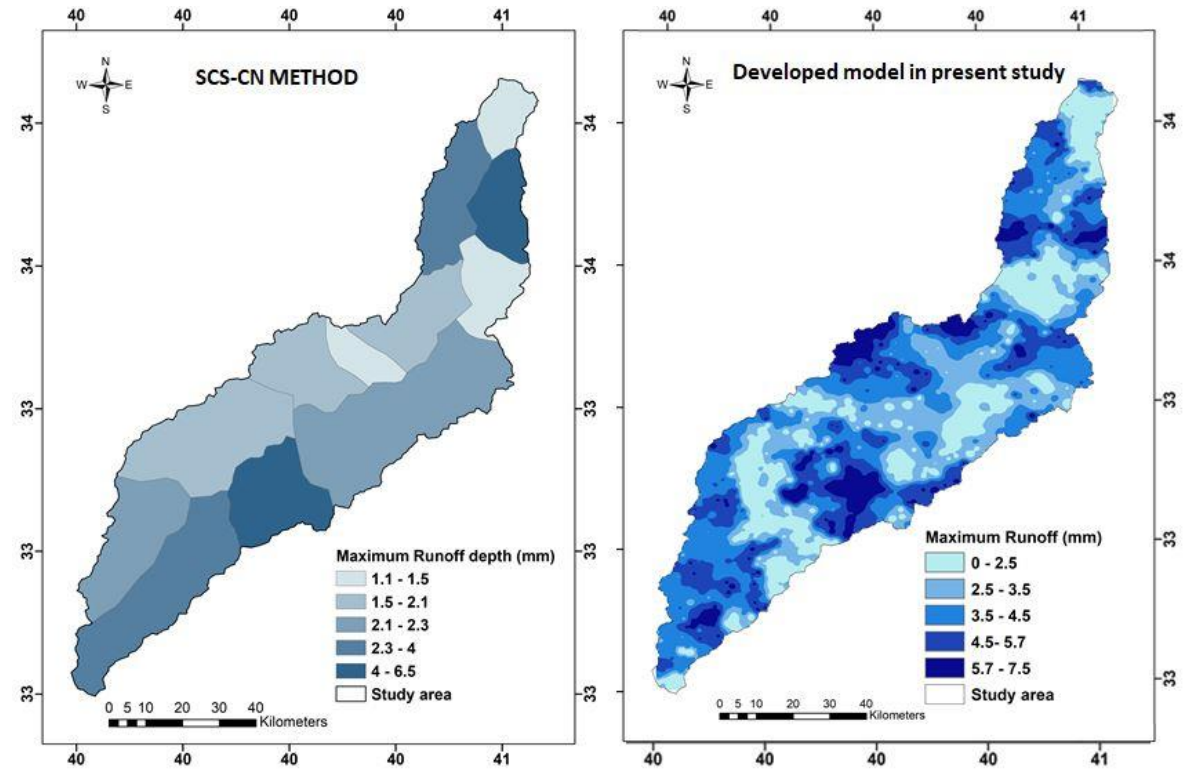

Figure 8. Comparison of runoff depth prediction in SCS-CN method and present model for storm event in 6-11-2018
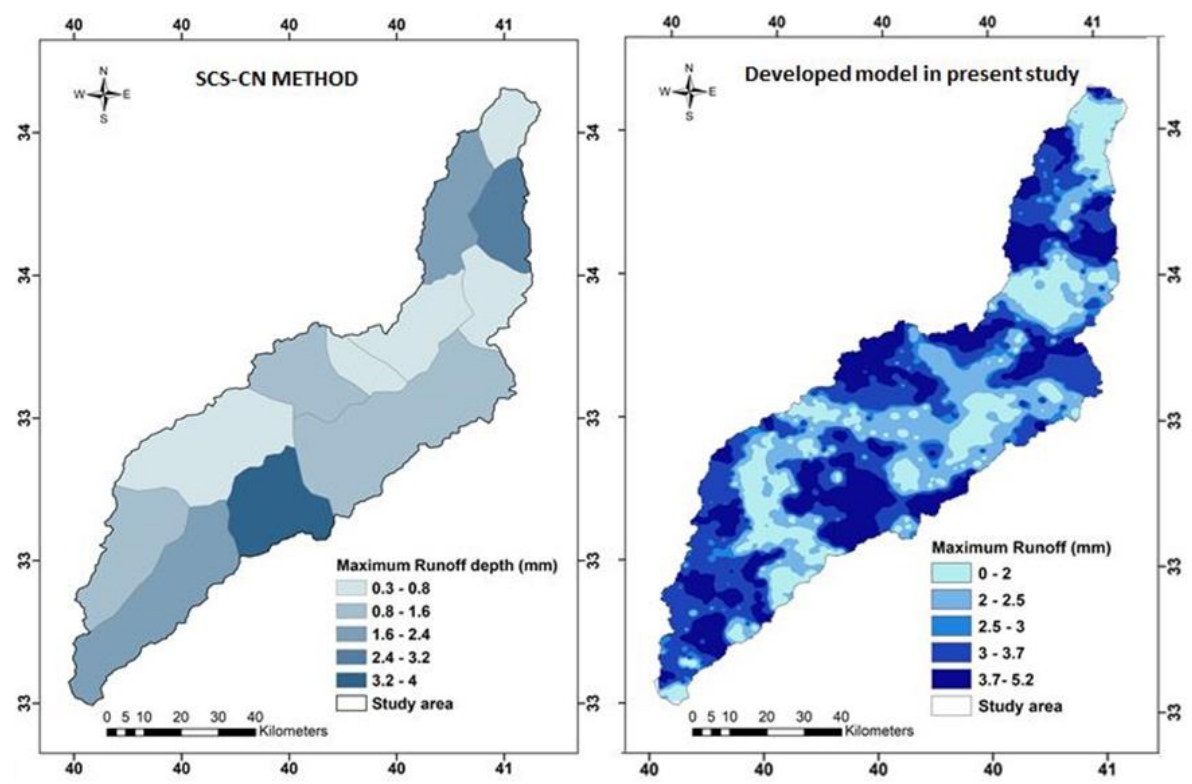

Figure 9. Comparison of runoff depth prediction in SCS-CN method and present model for storm event in 28-1-2019
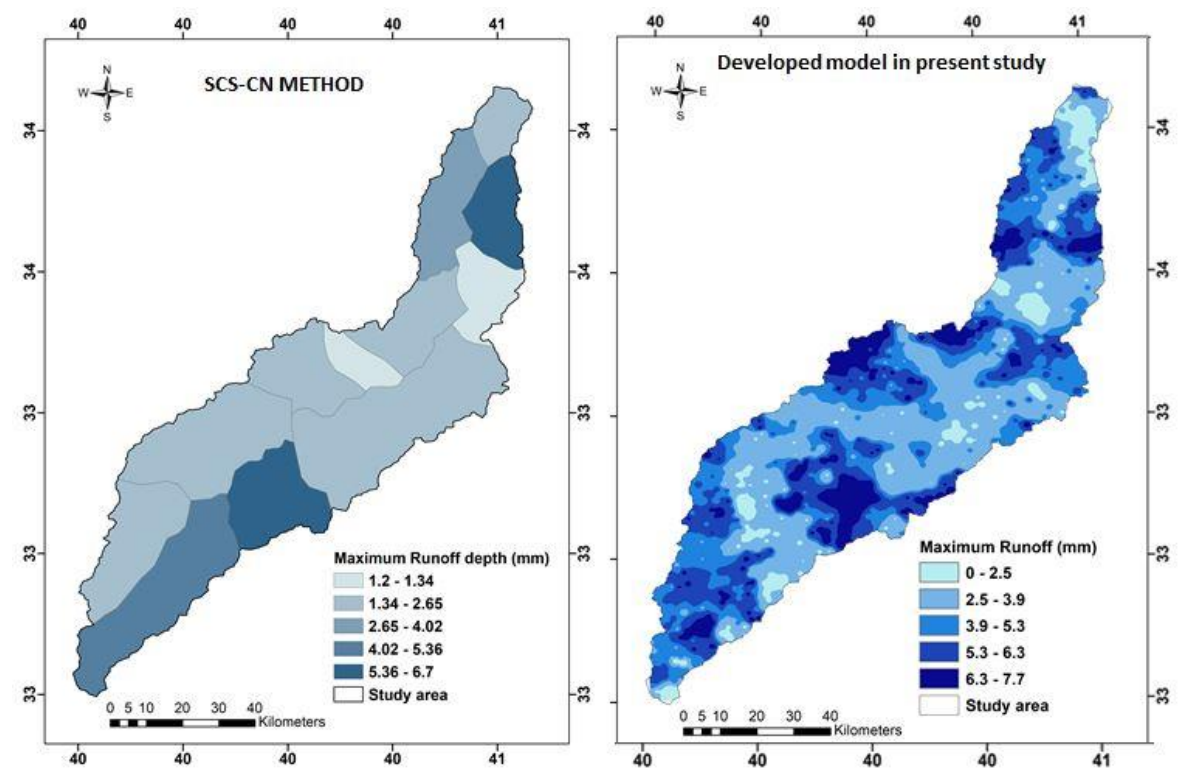

Figure 10. Comparison of runoff depth prediction in SCS-CN method and present model for storm event in 25-3-2019 

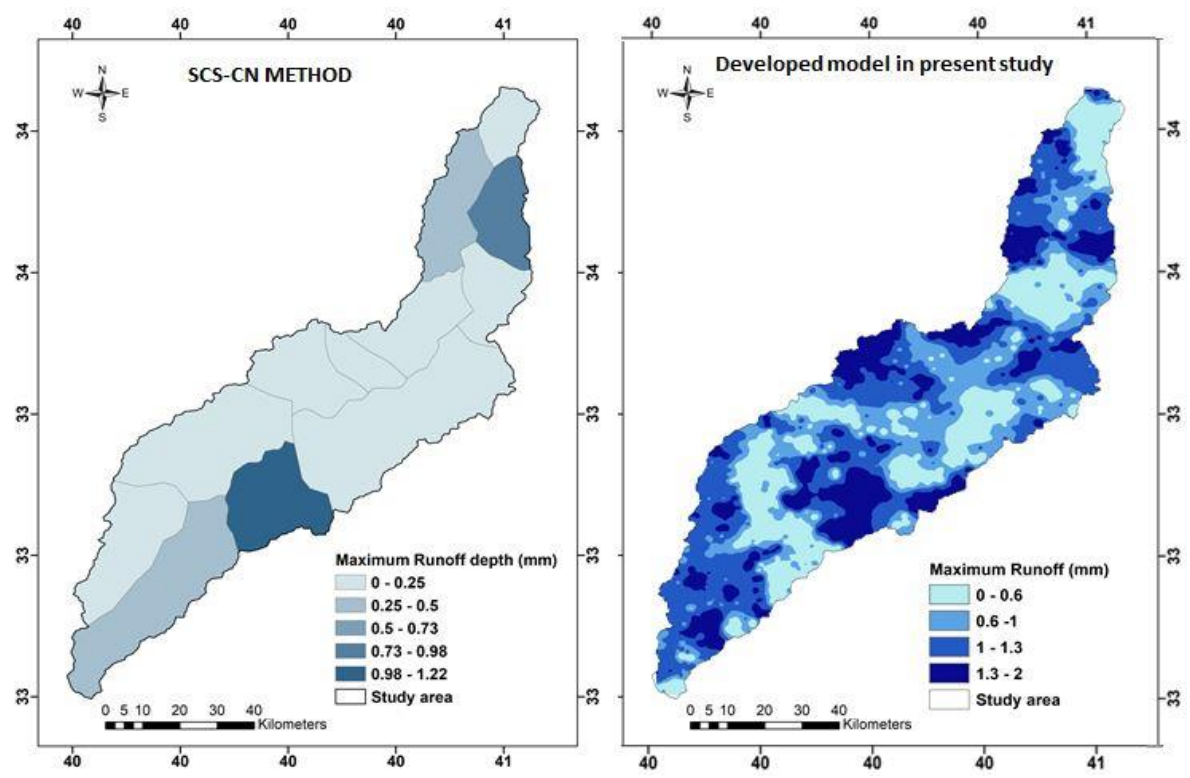

Figure 11. Comparison of runoff depth prediction in SCS-CN method and present model for storm event in 20-4-2019
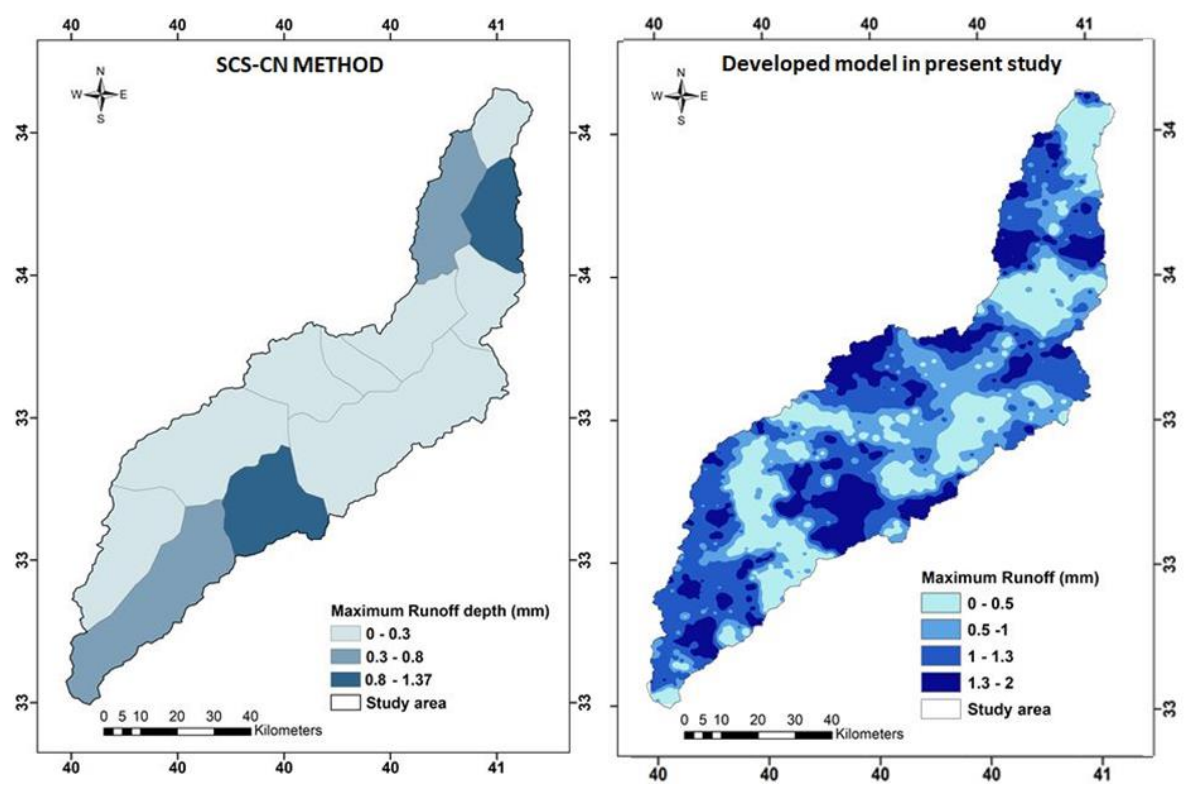

Figure 12. Comparison of runoff depth prediction in SCS-CN method and present model for storm event in 22-1-2020
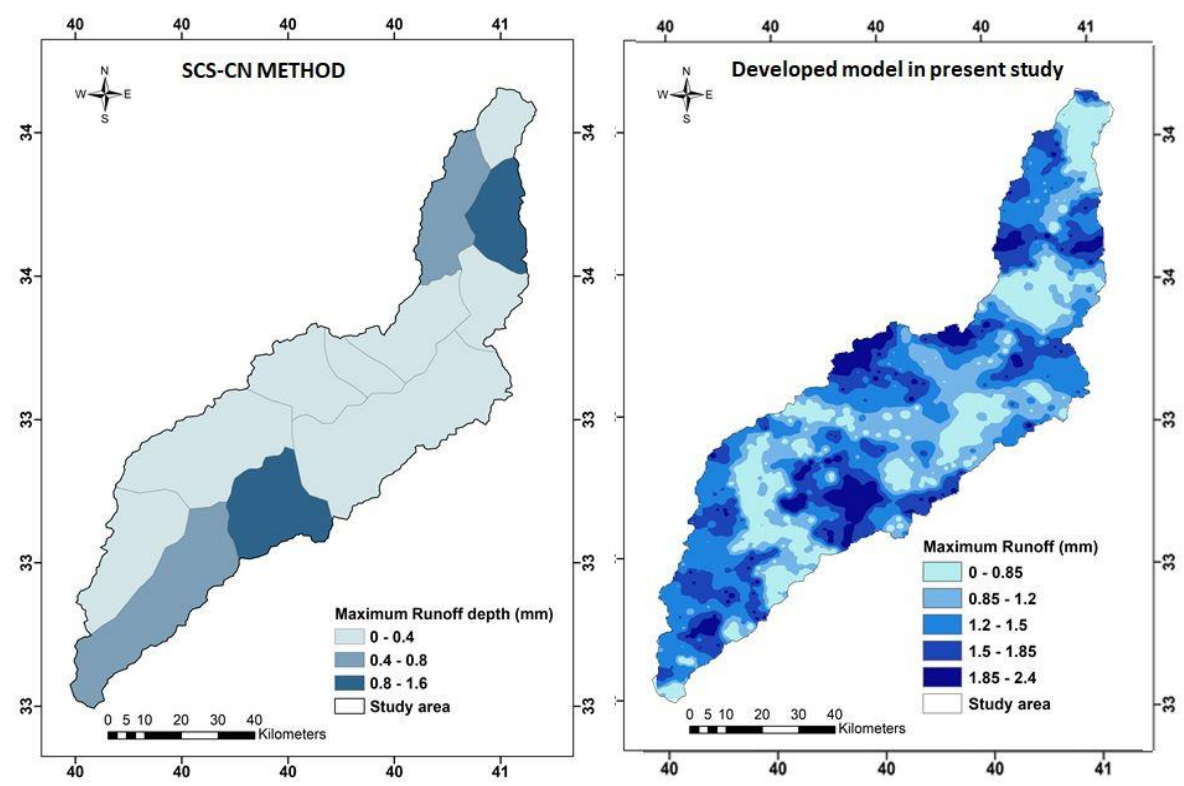

Figure 13. Comparison of runoff depth prediction in SCS-CN method and present model for storm event in 25-1-2020 


\section{ACKNOWLEDGMENT}

The authors would like to thank University of Anbar for its support to complete this work.

\section{REFERENCES}

[1] Sayl, K.N., Muhammad, A.S., Ahmed, A.D. (2020). GIS-based approach for rainwater harvesting site selection. IOP Conf. Series: Materials Science and Engineering, 737: 012246. https://doi.org/10.1088/1757899X/737/1/012246

[2] Sulaiman, S.O., Kamel, A.H., Sayl, K.N., Alfadhel, M.Y. (2019). Water resources management and sustainability over the Western desert of Iraq. Environmental Earth Sciences, 78: 495. https://doi.org/10.1007/s12665-0198510-y

[3] Khudhair, M.A., Sayl, K.N., Darama, Y. (2020). Locating site selection for rainwater harvesting structure using remote sensing and GIS. IOP Conf. Series: Materials Science and Engineering, 881(2020): 012170. https://doi.org/10.1088/1757-899X/881/1/012170

[4] Sayl, K.N., Muhammad, N.S., El-Shafie, A. (2017). Robust approach for optimal positioning and ranking potential rainwater harvesting structure (RWH): A case study of Iraq. Arabian Journal of Geosciences, 10(18): 413. https://doi.org/10.1007/s12517-017-3193-8

[5] Hashim, H.Q., Sayl, K.N. (2020). The application of radial basis network model, GIS, and spectral reflectance band recognition for runoff calculation. International Journal of Design \& Nature and Ecodynamics, 15(3): 441-447. https://doi.org/10.18280/ijdne.150318

[6] Bekhira, A., Habi, M., Morsli, B. (2018). Hydrological modeling of floods in the Wadi Bechar watershed and evaluation of the climate impact in arid zones (southwest of Algeria). Applied Water Science, 8(6): 185. https://doi.org/10.1007/s13201-018-0834-3

[7] Sayl, K.N., Muhammad, N.S., El-Shafie, A. (2019). Identification of potential sites for runoff water harvesting. Proceedings of the Institution of Civil Engineers: Water Management, 172(3): 135-148. https://doi.org/10.1680/jwama.16.00109

[8] Zhang, Y., Vaze, J., Chiew, F.H.S., Li, M. (2015). Comparing flow duration curve and rainfall-runoff modelling for predicting daily runoff in ungauged catchments. Journal of Hydrology, 525: 72-86. https://doi.org/10.1016/j.jhydrol.2015.03.043

[9] Gray, D.M. (1961). Synthetic unit hydrographs for small watersheds. Journal of the Hydraulics Division, 87(4): 33-54.

[10] Chow, V.T., Maidment, D.R., Mays, L.W. (1988). Applied Hydrology. McGraw-Hill Book Co, Singapore.

[11] Kamel, A.H. (2012). Evaluation of potential water harvesting in arid regions (case study Iraqi Western Desert). The International Journal of the Environment and Water.

[12] Li, F., Zhang, Y., Xu, Z., Liu, C., Zhou, Y., Liu, W. (2014). Runoff predictions in ungauged catchments in southeast Tibetan Plateau. Journal of Hydrology, 511: 28-38. https://doi.org/10.1016/j.jhydrol.2014.01.014

[13] Abdulla, F.A., Jumah, A.A., Adel, H.H. (2002). Single event watershed model for simulation runoff hydrograph in desert regions. Water Resources Management, 16(3):
221-238. https://doi.org/10.1023/a:1020258808869

[14] Hamer, W.D., Loveb, C.D., Booija, M.J., Hoekstraa, A.Y. (2007). A rainfall runoff model for two small ungauged catchment using the water balance of a reservoir for calibration. In Proceeedings 8th WaterNet/WARSFA/GWP-SA Symposium, 31 October - 2 November 2007, Lusaka, Zambia (CD-ROM). Harare, Zimbabwe: Waternet.

[15] Liebe, J.R., van de Giesen, N., Andreini, M., Walter, M.T., Steenhuis, T.S. (2009). Determining watershed response in data poor environments with remotely sensed small reservoirs as runoff gauges. Water Resources Research, https://doi.org/10.1029/2008WR007369 45(7).

[16] AlJawad, S.B., Al-Ansari, N. (2017). Evaluation of storm runoff in Wadi Hauran, Western Iraq. Journal of Environmental Hydrology, 25(6): 1-8.

[17] Bahat, Y., Grodek, T., Lekach, J., Morin, E. (2009). Rainfall-runoff modeling in a small hyper-arid catchment. Journal of Hydrology, 373(1-2): 204-217. https://doi.org/10.1016/j.jhydrol.2009.04.026

[18] Makungo, R., Odiyo, J.O., Ndiritu, J.G., Mwaka, B. (2010). Rainfall-runoff modelling approach for ungauged catchments: A case study of Nzhelele River sub-quaternary catchment. Physics and Chemistry of the Earth, Parts A/B/C, 35(13-14): 596-607. https://doi.org/10.1016/j.pce.2010.08.001

[19] Bartlett, M.S., Parolari, A.J., McDonnell, J.J., Porporato, A. (2016). Beyond the SCS-CN method: A theoretical framework for spatially lumped rainfall-runoff response. Water Resources Research, 52(6): 4608-4627. https://doi.org/10.1002/2015wr018439

[20] Sayl, K., Adham, A., Restisma, C. (2020). A GIS-based multicriteria analysis in modeling optimum sites for rainwater harvesting. Hydrology, 7(3): 51. https://doi.org/10.3390/hydrology7030051.

[21] Jain, A.K. (1989). Fundamentals of Digital Image Processing. Prentice-Hall, Inc.

[22] Achharya, T., Ray, A.K. (2005). Image Processing: Principles and Applications. John Wiley \& Sons, Inc., John Wiley \& Sons, https://doi.org/10.1002/0471745790

[23] Richards, J.A., Jia, X. (1999). Remote Sensing Digital Image Analysis. New York.

[24] ASTM. (2003). D3385-03 Standard test method for infiltration rate of soils in field using double-ring infiltrometer. Annual Book of ASTM Standards 04.08. Amer. Soc. Testing Materials, West Conshohocken, PA.

[25] Raghunath, H.M. (2006). Hydrology: Principles, Analysis, Design. Revised Second Edition. New Age International (P) Limited, Publishers 4835/24, Ansari Road, Daryaganj, New Delhi - 110002, 70-83.

[26] Taurino, A.M., Distante, C., Siciliano, P., Vasanelli, L. (2003). Quantitative and qualitative analysis of VOCs mixtures by means of a microsensors array and different evaluation methods. Sensors and Actuators B: Chemical, 93(1-3): 117-125. https://doi.org/10.1016/s09254005(03)00241-7

[27] Kennedy, J.B., Neville, A.M. (1986). Basic statistical methods for engineers and scientists. 3rd ed, Harper \& Row, New York, USA.

[28] Nash, J.E., Sutcliffe, J.V. (1970). River flow forecasting through conceptual models part I - A discussion of principles. Journal of Hydrology, 10(3): 282-290. https://doi.org/10.1016/0022-1694(70)90255-6 
[29] Ritter, A., Muñoz-Carpena, R. (2013). Performance evaluation of hydrological models: Statistical significance for reducing subjectivity in goodness-of-fit assessments. Journal of Hydrology, 480: 33-45. https://doi.org/10.1016/j.jhydrol.2012.12.004 